\title{
Reflexiones sobre la acción extraordinaria de protección y el arbitraje
}

\author{
Ana María Larrea de Ortiz*
}

Recibido/Received: 20/03/2020

Aceptado/Accepted: 29/09/2020

Sumario: 1. Introducción. 2. Procedencia de la acción. 3. Procedibilidad a la luz de la jurisprudencia de la Corte Constitucional. 4. Carácter taxativo de las causales de nulidad. 5. Posibilidad de presentar directamente una acción extraordinaria de protección. 6. Objeto del control constitucional. 6.1. Derechos constitucionales no renunciables. 6.2. Fallos de Corte Constitucional sobre distinción entre justicia ordinaria y justicia constitucional. 7. Causales constitucionales para la acción extraordinaria de protección 8. Conclusiones.

Resumen: Uno de los objetivos más deseables del arbitraje es la posibilidad de solucionar los conflictos privadamente, por personas bien entendidas en los pormenores de los conflictos patrimoniales transigibles, dentro de un plazo razonable, que se aspira sea inferior al de la justicia ordinaria. Por esta razón el arbitraje en nuestro país no es apelable, y es solo susceptible de control judicial mediante la acción de nulidad, y, excepcionalmente, de control de constitucionalidad mediante la acción extraordinaria de protección. Este artículo

\footnotetext{
Abogada especialista en Derecho Procesal y Máster en Derecho Procesal por Universidad Católica Santiago de Guayaquil. Especialista en Derecho Constitucional por Universidad de Salamanca. Doctora en Jurisprudencia por Universidad Técnica Particular de Loja. Socia de Larrea, Ortiz y Cía. Sociedad de Abogados. Árbitro de la Cámara de Comercio de Guayaquil. Directora del Centro de Arbitraje y Conciliación de la Cámara de Comercio de Guayaquil. Presidente de la Comisión del Estatuto del Jugador de la Federación Ecuatoriana de Fútbol. Correo electrónico: alarrea@1arreayortiz.com.
}

A. M. LaRRea de ORTiz, "Reflexiones sobre la acción extraordinaria de protección y el arbitraje", Revista Ecuatoriana de Arbitraje, No. 11, 2020, pp. 93-114. 
trata de profundizar sobre la correlación entre ambas acciones, la necesidad de agotamiento previo de la primera, el objeto real de la acción, y las últimas aportaciones dadas por la Corte Constitucional del Ecuador.

Palabras Clave: arbitraje, acción, control constitucional, nulidad, jurisprudencia, causales.

\section{Reflections on the extraordinary protection action and arbitration}

Aвstract: One of the most desirable objectives of arbitration is the possibility of resolving conflicts privately, by people who are well-versed in the details of transferable property conflicts, within a reasonable period, which is expected to be less than that of ordinary justice. For this reason, arbitration in our country is not subject to appeal, and is only subject to judicial control by means of an action for annulment, and then constitutional control by means of an extraordinary protection action. This article delves into the correlation between both actions, the need for prior exhaustion of the first, its real object, and the latest contributions given by the Constitutional Court of Ecuador.

KeYWorDs: arbitration, action, constitutional control, nullity, jurisprudence, causes.

\section{INTRODUCCIÓN}

Al haberse cumplido veinte años desde la expedición de la Ley de Arbitraje y Mediación (LAM), publicada en el Registro Oficial el 4 de septiembre de 19971, y siendo tal aniversario el motivo de una investigación previa, presentada

1. Ley de Arbitraje y Mediación, RO No. 417, 14/12/2006. 
en las jornadas académicas de octubre del 2017², se torna vital reflexionar sobre el camino recorrido por el arbitraje. Su aceptación, difusión y popularidad, así como su tratamiento desde la perspectiva constitucional, legal y judicial, esto es, analizar si las decisiones de los jueces han sido coherentes con la autonomía del arbitraje.

Desde la vigencia de la ley se han dictado dos Constituciones en 1998 y 2008, esta última recientemente celebró su décimo aniversario. Ambas elevaron a rango constitucional el arbitraje al incluir en sus artículos $191^{3}$ y 1904, respectivamente, una mención expresa de este como método alternativo de resolución de conflicto. Particularmente la Constitución de 2008 influyó sustancialmente en nuestro sistema jurídico al incorporar el modelo neoconstitucional, cuyo epicentro es el respeto y vigencia de los derechos fundamentales e insertarse dentro del llamado constitucionalismo latinoamericano, que en la región adoptaron Venezuela, Ecuador, Colombia y Perú. Al referirnos a este modelo, que tomó forma en Europa luego de terminada la Segunda Guerra Mundial, según indica PIETRO SANCHís, nos enfrentamos a "una constitución transformadora,

2. Ponencia presentada en la Conferencia de Arbitraje organizada por el Centro de Arbitraje y Conciliación de la Cámara de Comercio de Guayaquil y la Comisión Interamericana de Arbitraje Comercial, y actualizada luego de la expedición de las Sentencias No. 323-13/EP/19 y No. 31-14-EP/19 por la Corte Constitucional del Ecuador.

3. Constitución Política de la República del Ecuador, Artículo 191, RO No. 1, 11/08/1998.

"Art. 191.- El ejercicio de la potestad judicial corresponderá a los órganos de la Función Judicial. Se establecerá la unidad jurisdiccional.

De acuerdo con la ley habrá jueces de paz, encargados de resolver en equidad conflictos individuales, comunitarios o vecinales.

Se reconocerán el arbitraje, la mediación y otros procedimientos alternativos para la resolución de conflictos, con sujeción a la ley.

Las autoridades de los pueblos indígenas ejercerán funciones de justicia, aplicando normas y procedimientos propios para la solución de conflictos internos de conformidad con sus costumbres o derecho consuetudinario, siempre que no sean contrarios a la Constitución y las leyes. La ley hará compatibles aquellas funciones con las del sistema judicial nacional".

4. Constitución de la República del Ecuador, Artículo190, RO No. 449, 20/10/2008.

"Art. 190.- Se reconoce el arbitraje, la mediación y otros procedimientos alternativos para la solución de conflictos. Estos procedimientos se aplicarán con sujeción a la ley, en materias en las que por su naturaleza se pueda transigir.

En la contratación pública procederá el arbitraje en derecho, previo pronunciamiento favorable de la Procuraduría General del Estado, conforme a las condiciones establecidas en la ley". 
que pretende condicionar de modo importante las decisiones de la mayoría, pero cuyo protagonismo fundamental no corresponde al legislador, sino a los jueces ${ }^{5}$. Como comenta VelÁZQUEZ VelÁZQUEZ, el "neoconstitucionalismo evidencia el rol protagónico de la Constitución, es decir, que se trata no de un instrumento de carácter político, sino como un verdadero documento jurídico de aplicación directa e inmediata" ${ }^{\prime}$.

La acción extraordinaria de protección, que es el tema que analizaremos desde la perspectiva del arbitraje, es justamente una consecuencia de la Constitución de 2008. Al no tener precedentes en nuestro país, fue recibida con recelo y desconfianza, pues bajo el esquema anterior, el entonces Tribunal Constitucional no podía revisar ni alterar las decisiones de casación dictadas por la Corte Suprema de Justicia, entonces máximo organismo judicial del país?. Por lo cual, se consideraba que esta nueva posibilidad de revisión judicial era invasiva en cuanto a las competencias de la justicia ordinaria, y suponía una intromisión en esta, afectando su independencia y autonomía; así como un atentado a la seguridad jurídica, por la interminable dilación de las contiendas judiciales.

Conforme refieren García VILLENAS \& UpRIMMY YÉPEZ, citados por Velásquez VelásqueZ, las principales objeciones hacia la tutela sobre decisiones judiciales en Colombia tienen que ver con que hace chocar a las altas cortes, atenta contra la seguridad jurídica, es contraria al principio del juez natural y destruye la supremacía de la Corte Suprema y del Consejo de Estado como órgano de cierre de sus jurisdicciones8.

5. L. Pietro Sanchis, Derechos fundamentales, neoconstitucionalismo y ponderación judicial, Palestra Editores, 2007, p. 127.

6. S. Velázquez Velázquez, La Corte Constitucional del Ecuador y el Estado Constitucional de Derechos y Justicia, Atelier Libros Jurídicos, 2018.

7. Si bien el Tribunal Constitucional, durante su vigencia, difundió la noción de justicia constitucional, y fijó las bases para que la cultura jurídica ecuatoriana acepte su existencia, aquello no caló por distintas razones.

8. S. Velázquez Velázquez, N. 6, p. 280. 
Sin embargo, y a pesar de ciertos casos que pudieran evidenciar abuso y/o dedicatoria en el ejercicio de la acción, desde nuestra óptica, la actuación de la Corte Constitucional mayoritariamente ha contribuido a disipar las aprensiones iniciales, y ha sentado ciertas bases respecto al deber ser de la acción extraordinaria de protección, entendiendo que su finalidad es servir como límite a actuaciones arbitrarias de los jueces, que vulneren los derechos constitucionales y/o el debido proceso. $Y$, sobre todo, entendiendo su excepcionalidad y residualidad, pues no se trata de una nueva instancia, ni la Corte es tribunal de alzada, por lo que la mera inconformidad con la justicia o la legalidad de la decisión no tiene cabida, según sostuvo la misma Corte.

En tal sentido, la jurisprudencia ha aclarado que la acción no es una nueva instancia del proceso, y para explicarlo, ha recurrido a la teoría desarrollada por la Corte Interamericana de Derechos Humanos (CIDH), con relación a que dicha instancia internacional no constituye un nuevo recurso, ni busca reemplazar al juzgador ordinario, es decir, al juez que forma parte de la función judicial.

\section{Procedencia de la ACCión}

Cabe ahora revisar el escenario de su procedencia respecto del arbitraje. El artículo 94 de la Constitución contempla lo siguiente: "[1]a acción extraordinaria de protección procederá contra sentencias o autos definitivos en los que se haya violado por acción u omisión derechos reconocidos en la Constitución, y se interpondrá ante la Corte Constitucional. El recurso procederá cuando se hayan agotado los recursos ordinarios y extraordinarios dentro del término legal, a menos que la falta de interposición de estos recursos no fuera atribuible a 
la negligencia de la persona titular del derecho constitucional vulnerado"s.

Siendo el arbitraje un método de solución de controversias, su desenlace es el laudo, que es la decisión sobre el conflicto evidenciado en las pretensiones y sus excepciones. El artículo 32 de la LAM señala que "[1]os laudos arbitrales tienen efecto de sentencia ejecutoriada y de última instancia, y se ejecutarán de la misma forma que estas, mediante la vía de apremio"10. En consecuencia, los laudos arbitrales (inclusive los parciales o preliminares propios del arbitraje internacional) son resoluciones con fuerza de sentencia, susceptibles de control mediante acción extraordinaria de protección. Es más, se sostiene que el término "resolución con fuerza de sentencia" empleado en la norma quiso referirse a los laudos arbitrales.

La Corte Constitucional ha admitido reiteradamente las acciones extraordinarias de protección respecto de laudos arbitrales, por lo que hoy no es un tema que está en discusión. El debate sobre si cabe o no control constitucional en el arbitraje resulta retórico, pues en un Estado constitucional son absolutamente excepcionales los ámbitos exentos de control de constitucionalidad. La postura que se hace fuerte en el origen convencional del arbitraje, a efectos de considerarlo una institución autónoma, y, por tanto, al margen de dicho control; o aquella que se funda en el reconocimiento constitucional del arbitraje con sujeción a su ley reguladora, según la cual no cabe ningún otro recurso no previsto en ella ${ }^{11}$, llevan a una discusión que no es la que conviene mantener hoy en día. Lo

9. Constitución de la República del Ecuador, N. 4, Artículos 94 y 437.

"Art. 437.- Los ciudadanos en forma individual o colectiva podrán presentar una acción extraordinaria de protección contra sentencias, autos definitivos y resoluciones con fuerza de sentencia. Para la admisión de este recurso la Corte constatará el cumplimiento de los siguientes requisitos: 1. Que se trate de sentencias, autos y resoluciones firmes o ejecutoriados.

2. Que el recurrente demuestre que en el juzgamiento se ha violado, por acción u omisión, el debido proceso u otros derechos reconocidos en la Constitución".

10. Ley de Arbitraje y Mediación, N. 1, Artículo 32.

11. Ley de Arbitraje y Mediación, N. 1, Artículo 7. 
oportuno es definir cuál es el alcance de dicho control, a efectos de preservar la institución jurídica, a la luz del principio favor arbitri o favor arbitralis.

Siendo los principios mandatos de optimización, es decir, normas que ordenan que algo sea realizado en la mayor medida de lo posible, atendiendo a las realidades fácticas y jurídicas, el favor arbitri o favor arbitralis ${ }^{12}$ es una directriz que orienta la formulación y la aplicación de normas que, en última instancia, precautelen el derecho a la tutela efectiva de los ciudadanos, mediante la conservación de la vigencia del convenio arbitral, y la vigencia del laudo arbitral frente a intervenciones de justicia estatal, según sostiene JARA VÁSQUEZ ${ }^{13}$.

La Corte Constitucional ecuatoriana, en la Sentencia No. 169-12-2012 del caso EMVIAL, señaló con claridad que: “los convenios arbitrales, el proceso de arbitraje y su conclusión están limitados y vinculados por las normas constitucionales, al igual que todas las relaciones jurídicas y actos públicos y privados, más allá de que su origen pueda considerarse convencional. Es por ello que no puede ser admisible la aplicación de un convenio que verse sobre renuncia de derechos constitucionales, o un proceso arbitral que vulnere el debido proceso constitucional, o un laudo arbitral que falle en franca contradicción con la Constitución" ${ }^{14}$.

De igual forma, en el mismo caso, sostuvo: “[e]ntonces los laudos arbitrales tienen la misma fuerza que una sentencia ejecutoriada, lo que determina que sí pueden ser impugnados por medio de la acción extraordinaria de protección" ${ }^{\prime 15}$.

12. R. Alexy, Teoría de los Derechos Fundamentales, Centro de Estudios Políticos y Constitucionales, Madrid, 2008.

13. M. E. JARA VÁsquez, "Decisiones de la Justicia Estatal Ecuatoriana sobre el Arbitraje", Boletín Informativo Spondylus Universidad Andina Simón Bolivar, 2013.

14. Corte Constitucional del Ecuador, Sentencia No. 169-12-SEP-CC, Caso No. 1568-10-EP, 26/04/2012.

15. Ibídem. Véase igual criterio en Corte Constitucional del Ecuador, Auto de admisión, Causa No. 1585-10-EP, 11/03/2011. 
Suscribimos lo que sostiene el catedrático peruano PRIORI POSADA en cuanto que lo relevante son los límites al control constitucional, pues en la medida en que este se canalice adecuadamente, el arbitraje resultará fortalecido. Contrariamente a lo que podría pensarse, el que los laudos arbitrales resulten airosos a la revisión de constitucionalidad, será un elemento de consolidación y legitimación de la institución ${ }^{16}$.

\section{Procedibilidad a la luz de la jurisprudencia de la Corte Constitucional}

La Constitución introdujo en el artículo 94 como un requisito de procedibilidad, el agotamiento de todos los recursos ordinarios y extraordinarios previstos en la legislación, salvo que la falta de agotamiento no sea atribuible a negligencia del titular del derecho constitucional violado ${ }^{17}$.

Asimismo, el artículo 61 numeral 3 de la Ley Orgánica de Garantías Jurisdiccionales y Control Constitucional (LOGJCC) ${ }^{18}$ señala como requisito de la demanda, la demostración de haber agotado los recursos ordinarios y extraordinarios, salvo que sean ineficaces o inadecuados, o que la falta de interposición de estos recursos no fuere atribuible a la negligencia del titular del derecho constitucional vulnerado.

Sobre el tema, la Corte Constitucional anterior, en la referida Sentencia No. 169-12-2012 EMVIAL, se planteó la pregunta de si podía considerarse la interposición de una demanda de acción de nulidad de laudo arbitral como un recurso a ser agotado para habilitar la acción extraordinaria, y concluyó que cabía entender la acción de nulidad en sentido

16. G. Priori Posada, "El Control de Constitucionalidad de los Laudos en el Perú a la luz del Precedente Vinculante 146-2011", Revista Arbitraje Pontificia Universidad Católica del Perú, No. 2, 2012.

17. Constitución de la República del Ecuador, N. 4, Artículo 94.

18. Ley Orgánica de Garantías Jurisdiccionales y Control Constitucional, Artículo 61(3), RO(S) No. 52, 22/10/2009. 
amplio, como un "recurso en cuanto forma de solución de un vicio, sea sustantivo o adjetivo que afecte la providencia impugnada y en consecuencia es necesario agotarla de forma previa salvo que resulte inadecuada o ineficaz", conforme dispone el artículo 61 numeral 3 de la LOGJCC ${ }^{19}$.

Posteriormente, en Sentencia No. 123-13-SEP-CC, la Corte sostuvo "que la violación de derechos constitucionales puede producirse tanto por el órgano judicial que realiza el control del laudo en la acción de nulidad, como por parte del Tribunal Arbitral que expide el laudo, por lo que los laudos arbitrales son impugnables mediante acción extraordinaria de protección siempre que pretensión se relacione a vulneraciones constitucionales" ${ }^{20}$. Esta sentencia generó incertidumbre respecto a si era necesario o no agotar tal acción antes de acudir a la Corte Constitucional, alterando el precedente que de forma temprana y acertada había establecido la Sentencia No. 169-12-2012.

A continuación, en las Sentencias No. 113-15-SEP-CC de 8 de abril del 2015 y No. 171-17-SEP-CC del 7 de junio de 2017²1, la anterior Corte Constitucional admitió a trámite y se pronunció directamente sobre el fondo de los casos, sin determinar que los accionantes debieron agotar la acción de nulidad, lo que debió producir el rechazo preliminar de la acción, es decir, su inadmisión. Nuevamente, se creó incertidumbre sobre el requisito de procedibilidad contemplado en la Constitución.

Recientemente, las Sentencias No. 323-13-EP/1922 y No. 31-14-EP/1923 dictadas el 19 de noviembre del 2019, la Corte

19. Corte Constitucional del Ecuador, N. 14.

20. Corte Constitucional del Ecuador, Sentencia No. 123-13-SEP-CC, Caso No. 1542-11-EP, 19/12/2013.

21. Corte Constitucional del Ecuador, Sentencia No. 113-15-SEP-CC, Caso No. 113-15-SEP-CC, 08/04/2015; Corte Constitucional del Ecuador, Sentencia No. 171-17-SEP-CC, Caso No. 072516-EP, 07/06/2017.

22. Corte Constitucional del Ecuador, N. Sentencia No. 323-13-EP/19, Caso No. 323-13-EP/19, $19 / 11 / 2019$

23. Corte Constitucional del Ecuador, Sentencia No. 31-14-EP/19, Caso No. 31-14-EP/19, $19 / 11 / 2019$. 
abordó nuevamente el problema jurídico que analizamos, esto es, si, conforme los artículos 94 de la Constitución y 61 numeral 3 de la LOGJCC, es o no necesario agotar la acción de nulidad de laudo previo la presentación de una acción extraordinaria de protección. La Corte resolvió el tema de forma clara y contundente, con la finalidad de zanjar cualquier discusión originada en las decisiones de la anterior Corte, y sentar un precedente sólido a posteriori.

Así, aún cuando es en la fase de admisibilidad en que mayormente debería verificarse el cumplimiento de este requisito, y pese a que la Corte Constitucional anterior había puntualizado que, en virtud del principio de preclusión procesal, las exigencias previstas en dicha fase, ya no pueden ser revisadas una vez agotada esta ${ }^{24}$; la actual Corte estableció una excepción a la regla de preclusión y en una decisión -que no fue unánime-determinó que en situaciones en que se haya omitido el agotamiento de recursos, la Corte puede determinar su improcedencia y rechazar las acciones sin pronunciarse sobre el fondo, con el objeto de preservar el carácter extraordinario y residual en que se sustenta la justicia constitucional ${ }^{25}$.

\section{Carácter taxativo de las Causales de NUlidad}

La Corte considera que la acción de nulidad está diseñada para examinar vicios in procedendo, esto es, la tutela del debido proceso y el derecho a la defensa en el ámbito del proceso arbitral, por lo que el artículo 31 de la LAM contempla una

24. Corte Constitucional del Ecuador, Sentencia No. 037-16-SEP-CC, Caso No. 0977-14-EP, 03/02/2016.

25. Corte Constitucional del Ecuador, N. 23. "La acción de nulidad sería inadecuada cuando se hayan vulnerado derechos constitucionales o el debido proceso durante el proceso arbitral o en el laudo, cuya violación no pueda ser enmendada por las causales de nulidad del laudo establecidas en la Ley de Arbitraje y Mediación, pues el control que se efectúa en la acción de nulidad del laudo es diferente al control que realiza la Corte Constitucional a través de la acción extraordinaria de protección". 
serie de causales taxativas relacionadas a vulneraciones a diferentes elementos del debido proceso, que, verificadas, facultan al Presidente de la Corte Provincial de Justicia a anular el proceso arbitral hasta el momento anterior a que se produzca el vicio ${ }^{26}$.

Asimismo, acertadamente, la Sentencia No. 323-13-EP se pronuncia sobre la reserva legal de las causales, señalando que "la taxatividad de estas causales de nulidad se justifica en que esto brinda certeza en torno a las exactas situaciones jurídicas que podrían suponer la anulación de una decisión que tiene efectos de cosa juzgada, y como tal ha generado una legítima confianza en las partes procesales [...] Es por esto que, en materia de nulidades en general, siempre ha regido el principio de especificidad, que implica no hay nulidad sin texto, no hay nulidad sin ley" ${ }^{\prime 2}$.

De igual forma, acota la referida sentencia el beneficio que supone el carácter taxativo de las causales, con relación a la seguridad jurídica y principio de legalidad establecido en el artículo 226 de la Constitución ${ }^{28}$. De esta forma, concluye, "la acción de nulidad constituye un mecanismo adecuado y eficaz para la tutela del debido proceso arbitral que, necesariamente debe ser agotada cuando la supuesta vulneración se enmarque en una de las causales taxativas del artículo 31 LAM" $^{\prime 2}$.

Las sentencias en análisis son relevantes también en cuanto modifican, en este punto, el precedente de la anterior Corte en la Sentencia No. 302-15-SEP-CC, al sostener que existían dos causales de nulidad -falta de motivación y falta de

26. Ley de Arbitraje y Mediación, N. 1, Artículo 31.

27. Corte Constitucional del Ecuador, N. 22.

28. Constitución de la República del Ecuador, N. 4, Artículo 226. El carácter taxativo de las causales de nulidad garantiza el derecho a la seguridad jurídica de las partes procesales del arbitraje, quienes requieren certidumbre sobre las normas jurídicas bajo las cuales se efectuará el control judicial del laudo; así como el principio de legalidad establecido en el artículo 226 de la Constitución, según el cual el juez que conoce de la acción de nulidad del laudo puede ejercer solo las competencias y facultades que se le han atribuido en la Constitución y la ley.

29. Corte Constitucional del Ecuador, N. 22. 
competencia- que de oficio debían revisarse por quien conoce la acción de nulidad, aún sin ser invocadas, y sin constar en la ley $^{30}$. La actual Corte expresamente se aparta de este criterio, por considerar que atenta contra la taxatividad de las causales, que es consecuencia del principio de intervención mínima de la justicia ordinaria en el arbitraje. La sentencia incluye argumentos sólidos en beneficio a la autonomía y efectividad del arbitraje.

Así, sostiene que el reconocimiento constitucional del arbitraje en su artículo 190, además de hacer posible el acceso a este sistema alternativo de administración de justicia, mediante el respaldo a la autonomía de las personas, implica un pleno "aval" al arbitraje, reconociéndolo dotado de principios, normas y procedimientos propios. De lo anterior se tiene que su efectividad y vigencia necesitan del respeto de parte de la justicia ordinaria, hacia el arbitraje, por lo que no debe existir un control judicial indiscriminado y de oficio.

En la misma línea, la Sentencia No. 31-14-EP/19, del 19 de noviembre del 2019, enfatiza en que, existiendo convencionalmente una sustracción de la controversia frente a la justicia ordinaria, las partes deben acatar sus reglas, que incluyen la inapelabilidad del laudo y la posibilidad limitada de impugnación, conforme lo previsto en la ley especial que lo regula ${ }^{31}$. De otra forma, sería un despropósito el que habiéndose

30. Corte Constitucional del Ecuador, Sentencia No. 302-15-SEP-CC, Caso No. 0880-13-EP, 16/09/2015. "Si bien es cierto que la falta de competencia del tribunal arbitral y la falta de motivación del laudo arbitral no se encuentran dentro del catálogo de nulidades previstas en el art. 31, la jueza o juez y los árbitros, para garantizar el derecho constitucional al debido proceso en el desarrollo de cualquier procedimiento, estos tienen como primera obligación constitucional y legal, determinar su competencia por mandato del art. 76 numeral 7 literal $k$ ) de la norma suprema [...] Así mismo en cuanto a la supuesta falta de garantía de la motivación del laudo arbitral, alegada por la entidad demandante, el juzgador jamás puede prescindir aduciendo que ella no ha sido causal de nulidad, pues no se puede negar el enlace que existe con otras realidades jurídicas afines que destaca la noción del bloque de normas, entendido este como un conjunto de reglas que se integran por los demás preceptos jurídicos que extiende su conceptualización, sumando otros no contenidos en el art. 31, justamente para entender que la nulidad no se agota con una determinada norma, sino con una interpretación teleológica y sistemática del ordenamiento jurídico" (énfasis añadido).

31. Corte Constitucional del Ecuador, N. 23. 
acordado que la decisión del caso se adopte fuera de la justicia ordinaria, sea esta quien revise el fondo de las decisiones de los árbitros.

\section{Posibilidad de presentar directamente una ACCión EXTRAORDINARIA DE PROTECCIÓN}

Concluye la Corte en Sentencia No. 323-13-EP que, tratándose de otras causales no contempladas para la acción de nulidad del laudo, y que supongan una violación de derechos constitucionales y no una mera inconformidad con la decisión, se puede acudir directamente a la Corte Constitucional, sin presentar acción de nulidad; debiendo agotarse esta cuando la infracción si corresponda a una de las causales del artículo 31 LAM $^{32}$. En Sentencia No. 31-14-EP/19 se ratifica esta postura de la Corte, haciéndose énfasis en que las violaciones de derechos constitucionales no relacionadas a las causales de nulidad del laudo contenidas en la ley, pueden ser directamente reclamadas ante la Corte Constitucional a través de acción extraordinaria de protección ${ }^{33}$.

La decisión de la Corte Constitucional es coherente con lo que la doctrina especializada ha opinado sobre el tema. Así, el profesor CAIVANO sostiene que, si no existe causal para plantear la nulidad, pero sí para el recurso extraordinario, la parte debe acudir directamente a la justicia constitucional, pues si intenta agotar previamente la vía de nulidad, careciendo de causal que la habilite, perderá el recurso posterior por extemporáneo, toda vez que, por la aplicación de numerosos precedentes, la interposición de recursos improcedentes no suspende el plazo para deducir el recurso extraordinario. "La falta de causal para deducir el recurso o para interponer la acción de nulidad provoca una verdadera imposibilidad legal de acceder a

32. Corte Constitucional del Ecuador, N. 22.

33. Corte Constitucional del Ecuador, N. 23. 
la instancia judicial, lo que haría imposible agotar las vías ordinarias" ${ }^{34}$.

Como corolario de lo que se ha analizado, concluimos que, si coexistieren respecto de un laudo causales de nulidad y de acción extraordinaria de protección, sería necesario presentar ambas acciones simultáneamente, dentro de los términos que ambas prevén y evitando así la caducidad de cualquiera de las acciones. Esto aun a pesar de las dificultades prácticas y logísticas que se presentan.

Finalmente, no es necesario agotar los recursos de apelación y casación sobre la sentencia que se dicte en la acción de nulidad, pues tales recursos no proceden. A pesar de una trayectoria de desconcertante y cambiante jurisprudencia de la Corte Nacional de Justicia (CNJ), suscribimos los fallos de la $\mathrm{CNJ}$ que inadmitieron la casación al considerar que la acción de nulidad no es un proceso de conocimiento, entre ellos el Recurso No. 590-2012 ${ }^{35}$. Afortunadamente el tema quedó resuelto mediante Resolución No. 08-2017 del Pleno de la CNJ que contiene las Reglas para el Trámite de la Acción de Nulidad de Laudos Arbitrales, en los que se excluye todo recurso que no sea horizontal de aclaración o ampliación ${ }^{36}$.

\section{El objeto del control constitucional}

En relación con el fondo del control, reparamos en que las violaciones a derechos más frecuentemente alegadas son la tutela judicial efectiva, seguridad jurídica y debido proceso. Sobre tales alegaciones la Corte sostuvo, en Sentencia No.16912-2012, que los tres derechos se desarrollan a lo largo de toda la legislación infra constitucional, a través de reglas específicas

34. R. Caivano, El Control Judicial en el Arbitraje, AbeledoPerrot, 2011, p. 276.

35. Corte Nacional de Justicia, Sala Especializada de lo Contencioso Tributario, Recurso No. 5902012, 19/11/2013.

36. Corte Nacional de Justicia, Resolución No. 08-2017, 22/03/2017. 
y medios de impugnación que garantizan su aplicación por parte de las autoridades administrativas y judiciales, "siendo la existencia de dichas normas el cumplimiento mismo de la garantía constitucional" ${ }^{37}$. Señaló, asimismo, que la contravención de normas procesales conlleva una afectación constitucional solo mediata y de mera legalidad, que no se pueden conocer en sede constitucional por existir remedios suficientes en la justicia ordinaria ${ }^{38}$. Concluyendo que la única posibilidad de lograr un pronunciamiento favorable por medio de la acción extraordinaria de protección "sería la demostración de la existencia de una vulneración directa a una norma constitucional, fuera de lo considerado materia transigible y no de manera mediata" ${ }^{\prime 39}$.

Esta postura limita de forma importante la materia del control de laudos en sede constitucional, de forma coherente con lo que la doctrina ha reclamado en otros países, esto es, que no todo derecho constitucional pueda reclamarse, sino únicamente aquellos que no son susceptibles de disposición o renuncia.

\subsection{Derechos constitucionales no renunciables}

Así, a criterio de PRIORI POSADA, a propósito de analizar el precedente vinculante dictado por el Tribunal Constitucional Peruano en el conocido caso de Sociedad Minera de Responsabilidad Limitada María Julia ${ }^{40}$, existen dos tipos de derechos fundamentales que pueden ser vulnerados por un laudo arbitral: aquellos que a pesar de ser derechos fundamentales son disponibles (propiedad, libertad de contratación, libertad de empresa), y por tanto pueden ser objeto de discusión en un arbitraje; $y$, aquellos que versan sobre

37. Corte Constitucional del Ecuador, N. 14.

38. Ibídem.

39. Ibídem.

40. Tribunal Constitucional Peruano, Sentencia No. 00142-2011-PA/TC, 21/09/2011. 
las garantías mínimas que deben respetarse en un arbitraje para que, sea cual fuere la decisión, pueda entenderse que es válida constitucionalmente hablando.

Respecto de derechos fundamentales sobre los que las partes han decidido conferirles la facultad de decisión a los árbitros, no existe posibilidad alguna de revisión en el fondo, porque la Constitución reconoce la competencia de los árbitros para hacerlo. En esta línea, la construcción argumental que mejor refleja el panorama descrito es el voto de los Ministros Nazareno y Boggiano, en el caso Meller, según cita Caivano en que, si bien el análisis iba en la línea de la apelación en el arbitraje, los criterios son válidos en lo que nos ocupa. Allí se dijo que

“[...] nada obsta a que tratándose de asuntos disponibles para las partes, estas puedan excluir la revisión judicial, tanto más cuanto que en esos asuntos las partes son dueñas de someter la suerte de sus derechos a la apuesta o la suerte, o incluso renunciar a ellos. Tales alternativas son propias al arbitraje mismo, al que pueden quedar sujetas materias susceptibles de transacción, en que hay concesiones recíprocas guiadas por la equidad de los árbitros. Las partes pueden siempre, en asuntos disponibles para ellas, llegar hasta la renuncia de un derecho si esta alternativa conviene a sus intereses" ${ }^{\prime 1}$.

Ahora bien, respecto de las garantías mínimas que deben presentarse para que un laudo pueda ser considerado válido constitucionalmente hablando, sí cabe control de constitucionalidad pues esas garantías de validez son indisponibles, a diferencia de lo que ocurre con los derechos que se discuten.

Contrastando los derechos constitucionales garantizados que podrían afectarse en el arbitraje, entre ellos, propiedad privada, libertad de empresa, libertad de contratación, vemos que estos son esencialmente disponibles, y, en consecuencia, las

41. R. Caivano, N. 34, p. 103. 
partes bien pueden efectuar estipulaciones que a la postre los afecten, debiendo los árbitros acoger tales estipulaciones en sus fallos, en la medida en que se hayan adoptado libremente; sin que aquello implique un vicio reparable en sede constitucional. Cualquier afectación en este sentido se considera mediata, esto es, un asunto de mera legalidad, respecto del cual la Corte no se pronunciará a riego de excederse en sus atribuciones.

Admitir que la Corte ejerza control de constitucionalidad de decisiones judiciales, no supone que pueda declarar la nulidad de un contrato, o la procedencia de una indemnización de daños, por ejemplo, toda vez que ejercer un control desmedido, a la postre resulta en una actuación inconstitucional. Conforme sostiene VelázQuez VelÁZQUEZ ${ }^{42}$, la premisa que sustenta la acción extraordinaria de protección es la especialización del órgano en asuntos exclusivamente constitucionales; la Corte no resuelve temas legales, sino la violación de derechos constitucionales y normas del debido proceso, lo que debe distanciarla de la justicia ordinaria.

Adicionalmente debemos tener presente que los derechos constitucionales no son absolutos, bien pueden regularse mediante ley orgánica, sin afectar su núcleo fundamental, $y$ son potencialmente conflictivos con otros derechos constitucionales, lo que conlleva que se apliquen técnicas constitucionales para resolver, en el caso concreto, cuál derecho debe prevalecer. De lo que se concluye que, inclusive para el supuesto de derechos no disponibles, está claro que las alegaciones de inconstitucionalidad no necesariamente prosperarán. Es más, es de esperar que no solo respecto al control de laudos arbitrales, sino en general, el desenlace de las acciones extraordinarias que se presenten sea su desestimación, atendiendo a los requisitos de admisibilidad

42. S. Velázquez Velázquez, N. 6, p. 284. 
contemplados en el artículo 62 de la LOGCC ${ }^{43}$, y a la aspirada actuación constitucional de los operadores de justicia.

\subsection{Fallos de la Corte Constitucional sobre la distinción entre justicia ordinaria y justicia constitucional}

La Corte Constitucional ha emitido sucesivos fallos en los que enmarca su accionar y se distancia de la justicia ordinaria. Al efecto, la Sentencia No. 014-12-CC de la Corte Constitucional para el periodo de transición, dispuso: “[e]sta revisión no significa intromisión, pues la Corte Constitucional está por fuera de las funciones del Estado, y no es jerárquicamente superior a la autoridad máxima de la Función Judicial. No es la creación de una nueva instancia procesal, pues el control de la constitucionalidad de las sentencias se dará por excepción [...]"44.

De igual forma, en Sentencia No. 001-10-SEP-CC, la Corte indicó: “[e]1 juez constitucional no puede sustituir al juez ordinario; sin embargo, si le corresponde actuar ante evidentes actos antijurídicos de los jueces que conlleven contradicción a la Constitución por lesionar uno o más Derechos Humanos" ${ }^{\prime 4}$.

En lo tocante a la aplicación de normas adjetivas, la Corte Constitucional señaló en Sentencia No. 169-12-EP, que las causales para la interposición de la acción de nulidad contempladas en el artículo 31 LAM se refieren a actos de procedimiento que se diferencian del debido proceso constitucional "en cuanto los actos de procedimiento se encuentran establecidos en leyes procesales, y cuando estos no se han

43. Ley Orgánica de Garantías Jurisdiccionales y Control Constitucional, N. 18. Artículo 62. Según artículo 62 se necesita demostrar la relevancia constitucional del caso, la clara violación del derecho constitucional independientemente de los hechos, que la acción no se sustente solo en lo injusto de la decisión, que el sustento no sea solamente la falta de aplicación o errónea aplicación de la ley, o se refiera a la apreciación de la prueba por parte del juez, entre otros.

44. Corte Constitucional del Ecuador, Sentencia No. 014-12-SEP-CC, Caso No. 0776-10-EP, 06/03/2012.

45. Corte Constitucional del Ecuador, Sentencia No. 001-10-SEP-CC, Caso No. 0315-09-EP, $13 / 01 / 2010$. 
cumplido adecuadamente, provocan la nulidad o ilegalidad del acto, lo que permite al afectado obtener remedio en la justicia ordinaria"46. Mientras el debido proceso constitucional es la garantía de los derechos constitucionales del individuo, de la tutela efectiva de las libertades e intereses legítimos de las personas, los que se vulneran cuando se ha impedido el ejercicio de un derecho constitucional por la acción u omisión.

Encontramos confuso el anterior pronunciamiento de la Corte. Bien es cierto que las causales recogidas en los literales a, b y c del artículo 31 LAM, tienen que ver con el debido proceso y la tutela judicial efectiva, pues la falta de citación al demandado; de notificación de cualquier providencia; u omisión de práctica de pruebas, o traslado de estas, provoca indefensión a la parte afectada, y viola su derecho fundamental al debido proceso ${ }^{47}$. Por lo cual, deberíamos entender que, dado que tales causales encuentran remedio en la acción de nulidad, y como ya sabemos, debemos agotarla previamente, en principio, la reparación se producirá dentro de la justicia ordinaria, y solo por defecto, en la constitucional. Y no lo contrario, esto es, que tales causales nunca podrían ser materia de una acción extraordinaria de protección, en cuanto suponen una violación de derechos mediata, que encuentra remedio en los medios de impugnación de dicha justicia ordinaria.

Sobre el tema, GARCíA BELAUNDE ${ }^{48}$ afirma que las irregularidades procesales por sí mismas no son suficientes para que proceda un amparo, sino que se requiere la existencia de un proceso irregular, esto es un caso grave resuelto en última instancia, en que existan irregularidades estructurales, y siempre que se tenga certeza que sin la irregularidad el resultado del proceso sería otro. Pues de otra manera, sostiene, se abriría la puerta para obtener el mismo resultado.

46. Corte Constitucional del Ecuador, N. 14.

47. Ley de Arbitraje y Mediación, N. 1, Artículo 31.

48. D. García Belaunde, Derecho Procesal Constitucional, Editorial Temis, 2001, p. 166-167. 


\section{Causales constitucionales para la acción EXTRAORDINARIA DE PROTECCIÓN}

Debemos considerar otras posibilidades que, siempre de forma residual y excepcional, habilitarían la admisión, y eventualmente la reparación en sede Constitucional. En principio se trataría de la falta de motivación, en los términos del artículo 76 literal 1 de la Constitución, conforme ha venido desarrollando la Corte Constitucional; y falta de competencia del tribunal arbitral.

En cuanto a la falta de motivación, la Constitucional anterior, desarrolló en Sentencia No. 227-12-SEP-CC, el conocido test de motivación, conforme al cual, la garantía de motivación debía reunir los parámetros de razonabilidad, lógica y comprensibilidad, para considerarse cumplida ${ }^{49}$. Una de las últimas sentencias de la actual Corte Constitucional, la No. 280-13-EP, cuya ponente es la doctora NuQues MARTínez ${ }^{50}$, incluye un valioso análisis, y aporte al tema, en lo tocante a la sociedad como auditorio universal y destinatario extra procesal de la motivación de las sentencias.

En lo referente a la falta de competencia, si bien en principio, corresponde exclusivamente a los árbitros pronunciarse sobre su propia competencia, este principio kompetenz-kompetenz, junto al de favor arbitri no son absolutos, y podrían existir casos de grave irregularidad, que resulten reparables en esta vía, teniendo en cuenta que, ser juzgado ante el juez competente, es una de las garantías del debido proceso prevista en el artículo 76 numeral 3 de la Constitución ${ }^{51}$.

49. Corte Constitucional del Ecuador, Sentencia No. 227-12-SEP-CC, Caso No. 1212-11-EP, 21/06/2012.

50. Corte Constitucional del Ecuador, Sentencia No. 280-13-EP/19, Caso No. 280-13-EP, 25/09/2019.

51. Ibídem. 
En esta línea se pronunció el Tribunal Constitucional Peruano en el precedente María Julia ${ }^{52}$, al sostener que debe agotarse la instancia previa de anulación, en supuestos, que son también causales del recurso de anulación. La LAM no contempla tales causales para la nulidad de laudo, lo que, a la fecha, y mientras no se reforme adecuadamente la ley, implica la necesidad de acceder directamente a la Corte Constitucional para obtener una reparación. A nuestro criterio, la falta de disponibilidad de la materia o la inexistencia de convenio arbitral, constituyen justamente irregularidades procesales graves, y no meros incumplimientos formales, que pudieran analizarse y resolverse ante la Corte, mientras no constituyan causales de nulidad.

Así mismo, citamos los parámetros señalados en la sentencia precedente del citado Tribunal Constitucional Peruano en el 2011, en lo sustantivo o material cabe el control: (i) cuando se invoque la vulneración directa o frontal de los precedentes vinculantes establecidos por la Corte Constitucional sobre derechos constitucionales; (ii) cuando en el laudo se haya ejercido control difuso sobre una norma declarada constitucional; (iii) cuando la acción sea interpuesta por un tercero que no forme parte del convenio arbitral y se sustente en la violación directa o manifiesta de sus derechos constitucionales a consecuencia del laudo pronunciado ${ }^{53}$.

\section{Conclusiones}

La tasa de admisión de recursos de amparo constitucional en España es del 1\%54, y en Ecuador del 8\% deber ser, excepcional y residual, de la acción extraordinaria de protección, realidad a lo que no es ajena el arbitraje.

52. Tribunal Constitucional Peruano, N. 40.

53. Ibídem.

54. Congreso Nuevas Tendencias de Derecho Constitucional 19 al 21 de febrero del 2020, con la presencia de los Jueces de la Corte Constitucional, Guayaquil, Ecuador.

55. Ibídem. 
La acción extraordinaria no tiene por finalidad revisar situaciones de hecho o derecho que no sean del agrado de las partes, pues no se trata de una instancia más. Su admisión requiere el agotamiento de la acción de nulidad previo, cuando el vicio invocado sea también una causal de nulidad; por el contrario, cabe el acceso directo cuando no exista la causal, como sucedería en la falta de motivación, falta de competencia, inexistencia de convenio arbitral o indisponibilidad de la materia.

En cuanto a la violación constitucional, esta deber ser directa y debe referirse a derechos constitucionales no renunciables, como la seguridad jurídica, que sucedería si el laudo se hubiere fundado en normas jurídicas no vigentes, o contraviniere precedentes constitucionales vinculantes, o fuere presentada por un tercero a quien no se admitió en el arbitraje y cuyos derechos resultaren vulnerados.

Finalmente, considero que la Corte Constitucional ha realizado importantes aportes en beneficio de la vigencia y autonomía del arbitraje, y deberá continuar señalando el derrotero del objeto del control constitucional, sin intromisión en decisiones adoptadas legítimamente, como lo ha venido haciendo hasta aquí.

De esta forma, el arbitraje como institución, no ajeno ni por sobre la Constitución, resultará fortalecido. Cada acción extraordinaria que se inadmita, o rechace en el fondo, será un espaldarazo; e inclusive aquellas acciones que prevalezcan, dotarán de certeza a los operadores y usuarios del arbitraje, para mantenerlo dentro de los límites constitucionales. 